\title{
Basic Principles for Forming Teaching Staffs' Competitiveness in Vocational Training Institutions
}

\author{
Nina A. Ivanenko ${ }^{1}$, Sergei Y. Lavrentiev ${ }^{2}$, Elena G. Khrisanova ${ }^{3}$, Galina G. Tenyukova ${ }^{3}$, Liudmila V. \\ Kuznetsova $^{3}$, Sergei P. Yakovlev ${ }^{4} \&$ Nikolai M. Shvetsov $^{2}$ \\ ${ }^{1}$ Kazan National Research Technical University named after A. N. Tupolev, Kazan, Russia \\ ${ }^{2}$ Mari State University, Yoshkar-Ola, Russia \\ ${ }^{3}$ Chuvash State Pedagogical University named after I. Y. Yakovlev, Cheboksary, Russia \\ ${ }^{4}$ Branch of Saint-Petersburg State University of Engineering \& Economics, Cheboksary, Russia \\ Correspondence: Nina AndreyevnaIvanenko, Kazan National Research Technical University named after A. N. \\ Tupolev, K. Marks Street 10, Kazan, Tatarstan, 420111, Russia. E-mail: alfkazan@mail.ru
}

Received: January 19, 2014

doi:10.5539/res.v7n5p118
Accepted: February 22, 2015 Online Published: March 25, 2015

URL: http://dx.doi.org/10.5539/res.v7n5p118

\begin{abstract}
This article aims to identify and theoretically justify the basic principles for forming teaching staffs' competitiveness in vocational training institutions. The key categories in the identification of these principles were such concepts as: the competitiveness of a teacher, the competitiveness of teaching staff, thecorporate competition. The authors of the article have proposed the following principles for forming the competitiveness of teaching staffs in vocational education institutions: dialogic, transparency, corporativity and dynamism. The contents of this article can be useful for administrators and teachers of secondary and higher professional education, for researchers concerned with the formation of teachers' competitiveness, students, and for enhancing the competitiveness of colleges and universities.
\end{abstract}

Keywords: principles, teaching staffs, competitiveness, vocational training institutions

\section{Introduction}

Competitiveness in the modern labor market is largely dependent on the willingness to engage in multifunctional and increasingly complicated human activities, ona professional's possession of "integral characteristics of a competitive personality" (Ivanenko et al., 2015; Mitina, 2002): focus, flexibility (emotional, behavioral, and intellectual), competence, willingness to participate in professional contests.

\subsection{Competitiveness of a Teacher}

Speaking about the competitiveness of a teacher, positive competitiveness is meant, which manifests itself in cooperation, in mutually enriching dialogue, in an adequate choice of innovative technology "here and now", in finding "an individual style of activity" (Andreev, 2004; Levina et al., 2015; Biktagirova \& Valeeva, 2013; Valeeva \& Valeeva, 2013; Shaidullina et al., 2015), in readiness for "self-presentation"(Tamarskaya \& Azarov, 1999), in "self-competition"(Shaidullina \& Ivanenko, 2012; Ivanov et al., 2015; Khairullina et al., 2015; Shaidullina et al., 2014), in "fair competition"(Shaimakova, 2009) for all types of professional activities in which "equal competitors by the exertion of their creative energies become more competitive"(Shaidullina \& Ivanenko, 2012; Sakhieva et al., 2015; Vlasova et al., 2015).

There are several essential characteristics of vocational education institution teacher's competitiveness formation.

Firstly, the formation of the competitiveness of vocational education institution teacher is possible only in the case if the teacher is the subject of his profession-educational activities, who can independently set appropriate goals and achieve them through constructive evaluation of the work results. With all of this the teacher represents a creative, self-developing, intelligent, spiritually rich, free, humane, civically active, competitive personality; a person of culture; an educator; a teacher; a methodologist; a researcher.

Secondly, the competitiveness of a teacher of a vocational education institution consists in dynamism of personality characteristics, and therefore, it is appropriate to define its development as a result of a person's key 
competencies consistency formation, that make up the professionally-personal base of activities and his professional competence. As the core competencies of the teacher of a vocational education institution in the proposed research the following are considered: a) relating to the identity of a teacher as a subject of activity and communication (acmeological competency, including: axiological, self-improving, personal, psychological, reflexive and autopsychological); b) relating to social interaction of a teacher with the social environment (social competency, including: competency in the field of civic-social activities, socio-psychological, communicative, socially-perceptive); c) relating to profession-pedagogical activity of a teacher (educational competence, including: educationally-informative, competency in the field of independent cognitive activity, intellectual, profession-pedagogical) (Shaimakova, 2009; Levina et al., 2015; Mrathuzinaet al., 2015; ).

Thirdly, the development of the competitiveness of a teacher of a vocational education institution has its regularities in the formation of the complex of its profession-pedagogical abilities - designing, communicative, organizational, constructive, gnostic, perceptive/reflexive, and special.

Fourth, the development of the competitiveness of a vocational education institution teacher involves the mastery of the skills: 1) constructive self-assessment of his professionalism level development, pedagogical excellence and professional identity, individual style of activity and acmeological development, professional competence; 2) determination of the alignment of their such qualities as labor force with the requirements in the workplace; 3 ) searching and finding suitable employment, ability to persuade the employer of one's advantages over other candidates for the job.

Fifth, the formation of the competitiveness of a vocational education institution teacher means accounting of the negative consequences of competitive struggle for a teacher's personality (inability to achieve success in competitive struggle affects the self-esteem of the teacher, his self-depreciation, the manifestation of his individuality, creating conditions for professional strains and emotional burnout).

Sixth, the competitiveness development of a vocational education institution teacher is connected with his innovative activity, willingness to update the main elements of his personal innovation system - knowledge, technological equipment, information-communicative technologies and the conditions for their effective application, as well as susceptibility to anything new.

Consideration of the distinguishing features of a competitive teacher in particular, allows us to address the problem of competitiveness formation of the teaching staff members as a whole, namely, to identify and justify the principles of this process, ensuring effective corporate competition of the teaching staff.

\subsection{Corporate Competition of the Teaching Staff}

The essence of corporate competition is that it is the superiority of the joint actions resultof the teaching staff members, which in their singular and independent expression cannot provide the proper level of solving scientific-research, organizationally-pedagogical and methodological problems.

Whereas the superiority of a teaching staff project team lies in its diversity, i.e. the more members of various areas and levels there are in the team, the higher performance will be in its work, because of increased technological level of problem solving through a combination of diverse activity experience, enhancing in total the competitiveness of the entire team project. This complementing interprofessional interaction of young and experienced professionals contributes to forming the shared knowledge of the organization.

In this regard, the statement of Einstein is appropriate: "You cannot solve a problem using the same level of thinking that created this problem" and therefore, it is necessary to be able to use every opportunity to support others and to cooperate, because the whole is always greater than the sum of its parts, and alternative ways of other perception of the surrounding reality should not be ignored, as all members of the entire team can achieve something that is unattainable for each member individually.

In this regard, to ensure a positive corporate competition there should be greater opportunities to share experience of highly-qualified research scholars and specialists of scientific institutions in educational process and scientific research; to improve workforce capacity and skills of faculty members of higher and secondary vocational education institutions; attract faculty of secondary and higher education institutions, leading research scholars of research institutes and highly qualified specialists of enterprises for conducting scientific research in cooperation with postgraduates and undergraduate students in the earlier stages of education.

Corporate competition is feasible only through joint efforts of the teaching staff, suggesting a symbiosis of professional and research competencies, individual and subjective qualities of its members, reflexive-dialogic interaction of which is directed to the superiority of their team actions in dealing with the strategic objectives of the educational institution and in enhancing its competitiveness in the modern market of educational services. 


\section{Literature Review}

Development of the specialist competitiveness problem is sufficiently represented in the studies of modern scholars. There are the works of Virina (2007), Galuzo (2008), Lyapkina (2007) and others, devoted to the study of economics in developing competitiveness. The psychological aspect of this problem is considered in the works of Holodtseva, Portnova (2010), Podosinnikova (2006) and others. In the dissertational studies of Angelovski (2004), Bodyan (2009), Dushkina (2001), Kryvtsov (2008), Melnichenko (2004), and et cetera, there are different areas of implementing the pedagogical aspect of various specializations future professionals' competitiveness development disclosed in the learning process at the university (Fayzullina \& Saglam, 2014). However, the problem of forming competitiveness of the teaching staff is not adequately reflected in modern science, in particular, there are no studies on the identification and justification of the principles of this process, although studies of this kind are the actual trend in the theory and methodology of professional education.

\section{Methodological Framework}

As methodological grounds to identify and substantiate the principles of forming competitiveness of vocational education institutions teaching staffs there were the following categories:

-Competitiveness of a teacher, which is his integral characteristics, embodied in the symbiosis of his personally-professional, individual and subjective qualities, which form success of profession-educative activities for implementing the educational process in vocational training institutions. The indicators of the success of this activity, on the one hand, can be a teacher's satisfaction with his work and its results, successful personal fulfillment, the realization of person-professional potential, understood as the objective ability and the subjective desire to participate in competitive positions, produced in today's market of educational services. On the other-educating students as the future competitive specialists, and on the third hand - the society's recognition of the teacher's personality as a professional, possessing the optimal level of professionalism, teaching excellence and professional identity, an individual style of activity and a high level of acmeologic development;

-Competitiveness of the teaching staff, which is its integral characteristics, implying a symbiosis of professional and research competencies, individual and subjective qualities of its members, reflexive-dialogic interaction of which aims at superiority of their joint actions in addressing strategic problems of a vocational education institution and increasing its competitiveness in the modern market of educational services;

-Corporate competition, implying the superiority of the teaching staff's joint actions result, which is endowed with a common culture, values and objectives, where its members in their singular and independent expression cannot be competitive in the market of educational services.

\section{Results and Discussions}

\subsection{The Principle of Corporativity}

The most effective way to organize interaction within educational institutions appears to be the open educational system, which includes a set of interrelated educational elements, consisting in active collaboration with the social subsystems and each other through different types of resources to obtain competitive advantages through joining the efforts of two or more organizations (Ansoff, 2009; Laszlo, 1997; Milgram, 2001).

The presence of the synergism effect and the ability to control this effect creates a specific competitive advantage for the participants of such interaction, which is primarily manifested at the level of specific organizations, and which, ultimately, is implemented at different markets in the form of costs reduction level or in the form of purchasing goods and services (in this case, educational services), unique properties. The synergism strategy involves improving the performance by sharing resources (synergy of technologies and costs), market infrastructure (joint sale) or spheres of activity (planning and management synergy). The synergy strategy value is, thereby, in the fact, that it helps to get higher profitability of any production (process) within the relationship of institutions, than in a situation when they are managed separately.

Many economists believe the synergism is an important element in the selection, development and detailing of the development strategy of an organization. At the same time it is noted that the synergistic effect-no matter how potentially large it could be-will not occur by itself, it is necessary to plan and extract it. Educational practice also suggests that the effect of joint activity is always higher than the simple sum of individual efforts due to the increase of the potential for cooperation, relationships expansion. Thus, in the network, there are a new property being formed (the intellectual product) and the team owner. Since most of the processes in the network are self-organizing, then the integrative framework of uniting institutions and teachers is the consulting support of project activities to form the content and organize education in the universum of innovation culture, 
manifested as advisory services in the development of educational programs of educational institutions, educational institutions or territories development programs, research and management projects, and others. The team of like-minded people who are ready to integrate their efforts towards achieving the objectives of the network has a single vision of the future, understanding of the present, awareness of the need for changes and the availability of the complete corporate culture in an educational institution. All of the above justifies the choice as one of the leading principles of the teaching staff competitiveness formation-the principle of corporativity, suggesting solidarity in professional goals and values of the teaching staff members, aimed at implementing joint professional activity to enhance the effectiveness of the college educational process.

\subsection{The Dialogic Principle}

In terms of synergetics, in the organization of corporate positive competition, the important is not to transfer knowledge, but learning the basics of self-education mastery, the use of non-linear dialogue, awakening to self-training and others. Under the non-linear dialogue-its openness is understood, forward and backward linkages in the same tempo-world, where the subjects of the educational process (teachers, instructors, administration) cooperate, promoting mutual positive changes, that is the task of the administration is in a small resonant action on the team of teachers, followed by ensuring its self-development. Such cooperation is feasible only on the condition of mutual self-actualization of creative abilities. And it is very important here that this happens only in good mutual understanding and empathy of each other's personal development. In this regard, as relevant acts the dialogic principle, involving a reflective dialogue of teachers to effectively interchange the existing potential to predict and solve strategic objectives of the vocational education institution. Here an important role is played by a value-orientation unity of the college teaching staff, aimed at useful joint activity to improve its competitiveness, the effectiveness of which can only be achieved in reflexive-dialogical interaction of its subjects.

Designing complex systems cannot ignore the basic rules of design. Thus, the sub-optimization rules say that independent optimization of each subsystem does not lead to the optimization of the overall system (Vladislavlev, 1978). In this case, it means that corporate competition at some stage will not lead to positive results, as for the improvement and development of the teaching staff as a whole systematic professional development of its members is necessary. This is possible with a high level of data collection and processing, and provided that the subject of educational activities is able to engage in information exchange with the external environment from any point of the trajectory of his professional advancement.

During the active professional self improvement a teacher has qualitative and quantitative changes that need to change the requirements for this process, as well.

\subsection{The Principle of Transparency}

A system is called self-organizing, if it without any specific external influence acquires a functional structure. Ensuring transparent quality information support, determined by the purpose of training, the nature of the students' future careers, resources and learning outcomes, as well as the very transparent procedure for assessing the progress of teachers, leads to the creation of a specific competitive environment among faculty staff. In terms of an integrated set of "Technical College-KNRTU" on the basis of the widespread use of multi-agent networks of the open architectural type and the virtual access to education-project base, the teachers rating is implemented. In this regard, we propose the principle of transparency, implying openness and accessibility of teachers' achievements in order to maintain a competitive environment in the team for the timely adjustment of their achievements.

\subsection{The principle of dynamism}

The next no less important condition for forming competitiveness of the teaching staff is its dynamism, whereby in response to changes in internal and external influences, it is able to establish the new, corresponding balances both within themselves and with the environment of its functioning. Distinguishing the principle of dynamism involves continuous development, self-development and improvement of the teaching staff members in order to maintain competitive advantages of the college as a whole for its adaptation to the changing socio-economic conditions.

\section{Conclusions}

Thus, as the principles of forming the competitiveness of the college teaching staff, we have identified the following: the dialogic principle, involving a reflexive dialogue of the teaching staff members for the effective interchange of the existing potential for forecasting and solving strategic problems of the college; the principle of transparency, implying openness and accessibility of the teaching staff members' achievements, in order to 
maintain a competitive environment; the principle of corporativity, suggesting a solidarity in professional goals and values of the teaching staff members, to implement joint professional activity for enhancing the effectiveness of the college educational process; the principle of dynamism, involving continuous development, self-development and improvement of the teaching staff members in order to maintain competitive advantages of a college as a whole for its adaptation to the changing socio-economic conditions.

\section{References}

Andreev, V. I. (2004). Konkurentology, Training course for creative self-development of competitiveness. Kazan.

Angelovski, A. A. (2004). Formation of competitiveness of students in the course of vocational training in high school ( $\mathrm{PhD}$ Thesis). Magnitogorsk.

Ansoff, I. (2009). Strategic Management (p. 344). St. Petersburg, Peter.

Biktagirova, G. F., \& Valeeva, R. A. (2013). Technological approach to the reflection development of future engineers. In 2013. International Conference on Interactive Collaborative Learning (p. 427). ICL. http://dx.doi.org/10.1109/ICL.2013.6644615

Bodyan, L. A. (2009). Development of the competitiveness of a technical college students on the basis of context-modular approach ( $\mathrm{PhD}$ Thesis). Magnitogorsk.

Dushkin, O. V. (2001). Formation of competitiveness of students of secondary specialized educational institutions of trade and economic profile ( $\mathrm{PhD}$ Thesis). Lipetsk.

Fayzullina, A. R., \& Saglam, F. A. (2014). Methods and forms of organization of training activities on the lessons of history. History teaching in school, 9, 45-50.

Galuzo, E. A. (2008). Development of the Competitiveness of staff of construction companies (PhD Thesis). Moscow.

Holodtseva, E. L., \& Portnova, A. G. (2010). Akmeology subject of professional work (p. 191). Publisher Kemerovo State University.

Ivanenko, N. A., Akhmetov, L. G., Lavrentiev, S. Y., Kartashova, E. P., Lezhnina, L. V., Tzaregorodtzeva, K. A., \& Khairullina, E. R. (2015). Features of Modeling the Formation of Teaching Staff Competitiveness. Review of European Studies, 7(3), 37-42. http://dx.doi.org/10.5539/res.v7n3p37

Ivanenko, N. A., Khairova, I. V., Fajzrakhmanova, A. L., Khalilova, T. V., Kharisova, G. M., Lisitzina, T. B., \& Shaimukhametova, S. F. (2015). Competitiveness of Professional Education: Purposes, Tasks and Factors of Its Participation in the International Educational Services Market. Asian Social Science, 11(1), 369-374.

Ivanov, V. G., Shaidullina, A. R., Drovnikov, A. S., Yakovlev, S. A., \& Masalimova, A. R. (2015). Regional Experience of Students' Innovative and Entrepreneurial Competence Forming. Asian Social Science, 11(1), $35-40$.

Khairullina, E. R., Valeyev, A. S., Valeyeva, G. K., Valeyeva, N. S., Leifa, A. V., Burdukovskaya, E. A., \& Shaidullina, A. R. (2015). Features of the Programs Applied Bachelor Degree in Secondary and Higher Vocational Education. Asian Social Science, 11(3), 213-217.

Kryvtsov, R. A. (2008). Formation of the competitive expert in the process of professional environmental education in high school (PhD Thesis). Nizhny Novgorod.

Laszlo, E. (1997). Tracks leading into the coming millennium: Problems and prospects. Vieta, 4, 87-88.

Levina, E. Y., Akhmetov, L. G., Latipova, L. N., Mirzagitova, A. L., Mirzanagimova, F. I., Latipov, Z. A., \& Masalimova, A. R. (2015). Diagnostics of Educational Activity Quality on the Basis of Qualitative Methods. Asian Social Science, 11(4), 246-251.

Levina, E. Y., Yunusova, A. B., Fayzullina, A. R., Rassadin, S. V., Lotfullin, M. R., Nuriyeva, E. N., \& Vlasova, V. K. (2015). Federal Public Administration Implementation in Vocational Education. Review of European Studies, 7(4), 98-104. http://dx.doi.org/10.5539/res.v7n4p98

Lyapkin, N. A. (2007). Competitiveness staff in terms of its aging: The example of machine-building enterprises of Rubtsovsk (PhD Thesis) (p. 160). Bijsk.

Melnichenko, T. Y. (2004). Formation of competitiveness of the future expert in the study of economics $(\mathrm{PhD}$ Thesis). Kaluga.

Milgram, S. (2001). Experiment in social psychology (p. 336). Peter. 
Mitina, L. M. (2002). Developmental Psychology competitive personality (p. 440). Moscow-Voronezh.

Mrathuzina, G. F., Fayzullina, A. R., \& Saglam, F. A. (2015). Substantive, Methodological and Organizational Discourse in Oriental History Learning at School and University. Review of European Studies, 7(1), 57-62.

Podosinnikova, E. A. (2006). Psychological conditions of development of competitiveness of young professionals in the course of professional work (PhD Thesis) (p. 180). Moscow.

Sakhieva, R. G., Ibatullin, R. R., Biktemirova, M. K., Valeyeva, G. K., Pchelina, O. V., Valeyeva, N. Sh., ... Khairullina, E. R. (2015). The Essential, Objective and Functional Characteristics of the Students' Academic Mobility in Higher Education. Review of European Studies, 7(3), 335-340. http://dx.doi.org/10.5539/res.v7n3p335

Sakhieva, R. G., Khairullina, E. R., Khisamiyeva, L. G., Valeyeva, N. S., Masalimova, A. R., \& Zakirova, V. G. (2015). The Syllabus of the Regional Component of Professionally Motivational Education Developed for the Students Specializing in Tourism. Asian Social Science, 11(2), 246-251.

Shaidullina, A. R., \& Ivanenko, N. A. (2012). Mechanisms for the preparation and selection of future competitive technical specialists. Professional education in Russia and abroad, 3(7).

Shaidullina, A. R., Masalimova, A. R., Vlasova, V. K., Lisitzina, T. V., Korzhanova, A. A., \& Tzekhanovich, O. M. (2014). Education, science and Manufacture Integration Models features in Continuous Professional Education System. Life Science Journal, 11(8s), 478-485.

Shaidullina, A. R., Merzon, E. E., Zakirova, V. G., Mokeyeva, E. V., Karev, B. A., Burdukovskaya, E. A., \& Polevaya, N. M. (2015). The Peculiarities of Perspective Students Selection Mechanism by the Future Employers-Enterprise. Review of European Studies, 7(1), 68-73.

Shaimakova, J. B. (2009). The role of innovative competence in the development of competitive high school teacher ( $\mathrm{PhD}$ Thesis) (p. 248). Tomsk.

Tamarskaya, N. V., \& Azarov, L. A. (1999). Management culture of the teacher as a pedagogical problem. In Actual problems of general and vocational teacher education (pp. 70-73). Kaliningrad.

Valeeva, L. A., \& Valeeva, R. A. (2013). Development of future engineers' critical thinking in foreign language teaching. In 2013 International Conference on Interactive Collaborative Learning (p. 438). ICL. http://dx.doi.org/10.1109/ICL.2013.6644619

Virin, I. V. (2007). Formation and development of the competitiveness of young professionals in the labor market (PhD Thesis) (p. 186). Moscow.

Vladislavlev, A. P. (1978). Continuing education as a method of forming a fully developed personality. Philosophical Sciences, 5, 3-15.

Vlasova, V. K., Kirilova, G. I., \& Masalimova, A. R. (2015). Information and Logistic Foundations of Pedagogical Education Design and Content Education. Review of European studies, 4(7). http://dx.doi.org/10.5539/res.v7n4p54

\section{Copyrights}

Copyright for this article is retained by the author(s), with first publication rights granted to the journal. This is an open-access article distributed under the terms and conditions of the Creative Commons Attribution license (http://creativecommons.org/licenses/by/3.0/). 